\title{
Relevant resources for teaching and learning information systems design at higher education institutions
}

\author{
M. Jakovljevic* \\ School of Economics and Business Sciences \\ University of the Witwatersrand \\ Johannesburg, South Africa \\ e mail: jakovm@sebs.wits.ac.za \\ * D.Ed. Student at Rand Afrikaans University
}

\section{P. Ankiewicz}

Department of Mathematics, Science, Technology and Computer Education

University of Johannesburg

Johannesburg, South Africa

e mail: pieta@uj.ac.za

\section{E. de Swardt}

Department of Mathematics, Science, Technology and Computer Education

University of Johannesburg

Johannesburg, South Africa

e mail: estelleds@uj.ac.za

\begin{abstract}
One of the major obstacles facing project managers and information system designers is creating an appropriate environment to excel system design skills. Instructors in Information System Design (ISD) environments are responding to the increasing demands posed by time and complexity through investigating a variety of tools, system design methodologies and software technologies. The intention is to help students/information system designers to take more control over their own learning process and to demonstrate system design skills.
\end{abstract}

The purpose of this article is to identify and discuss the relevant resources, which could enhance the teaching and learning processes necessary for ISD created through the Instructional Web Design Programme (IWDP) motivating the students to excel while trying to learn and understand concepts, and techniques that relate to information systems. This research was based on a qualitative, action research approach where individual interviews, focus group interviews, observation and document analysis were used to gather data (Yin 1994; Merriam 1998). Seventeen students at an institution of higher education were observed and their experiences were investigated through a focus group interview, journals and essays. In addition, an interview with the lecturer was performed to investigate her thoughts and feelings during the implementation of the IWDP. The most important findings were: Available physical, human and financial resources and their components set a basis for creating an effective climate for teaching of information system design; the 
components embedded within the physical, human and financial resources assist students in obtaining an understanding of design procedures.

\section{INTRODUCTION}

Though numerous research reports have provided a body of information about a wide range of techniques in software design and development (Greenberg and Lakeland 1999; Shelly, Cashman and Rosenblatt 2001) far less research has been conducted on those aspects of software analysis and design that meet the design needs of students in an Information Systems Design (ISD) environment. 'Information systems is an inter-disciplinary field of scholarly inquiry, where information, information systems and the integration thereof with the organization is studded in order to benefit the total system (technology, people, organizations and society)' (Roode 2005).

There is little in the research literature on mind tools and graphical techniques that will engage students in the development of system design skills. Mind tools are computer tools that are intended to engage and facilitate the cognitive processing of students (Kozma 1987; Kommers, Jonassen and Mayers 1992; Jonassen 1996).

Students should be involved in informal learning activities such as knowledge sharing, experimentation and environmental scanning in order to achieve reflective learning (Lohman 2000). There are no studies, however, which indicate what resource components could promote such environment, particularly in the ISD context. The ISD learning and teaching context, which is characterised by great pressure, complex demand and a lack of time for learning, possibly could be improved if we know how to identify and then integrate the features of an appropriate environment for ISD in the presentation of a learning programme.

For the purpose of this study, on which the article reports, an Instructional Web Design Programme (IWDP) has been developed and implemented to help students fulfil the complex, multiple tasks of problem solving during an information system analysis and design. The program was based on the new outcomes-based (OBE) school curriculum in South Africa, which is aimed at developing creative problem solving skills in every learning area (DoE 1997b; South Africa 1997). OBE focuses, amongst others, on critical thinking, effective communication, and problem solving (Jakovljevic 2002).

The system design methodology incorporated in the Instructional Web Design Programme (IWDP) is tailored in such a way to allow students to take into the consideration the necessary tasks and activities to be performed, the knowledge base that must be developed and the expected learning outcomes.

The research questions addressed in this article are:

1. What are the resource components for enhancing teaching and learning in ISD context? 
2. How can one incorporate these resource components in a learning programme for students at an institution of higher education (HEI)?

3. What are the effects of these components for enhancing teaching and learning in ISD context on students' understanding of concepts and techniques that relate to information system design?

The purpose of this article is to identify the resources and their components, which could enhance the teaching and learning processes for ISD, to discuss their incorporation within the IWDP and to discuss the effects of these components on teaching and on the students' understanding of design procedures.

\section{RESOURCES IN INFORMATION SYSTEMS DESIGN CONTEXT}

To help students develop a deeper understanding of ISD and to expand their thinking skills, knowledge and values the following resources are considered essential:

- Physical resources

- Human resources

- Financial resources

This research asserts that physical, human and financial resources provide students and the lecturer with an appropriate environment for learning and teaching ISD. The resources are inter-dependent and interact with each other to form a dynamic structure for teaching and learning in a project-based classroom.

\section{Physical resources}

Organising the physical environment could facilitate learning transfer as the learning process of ISD is embedded in the classroom environment and real-world environment, thus fulfilling the enabling factors of informal education (Jakovljevic 2002). 'The importance of informal learning in professional development has focused greater attention on the interplay between informal learning and the organizational environment where this learning occurs' (Lohman 2000).

The following variety of physical resource components will help to arrange the learning environment so that it is more conducive to self-initiated engagement with ISD:

(a) Venue (Computer lab): Organising the physical appearance of the computer lab as a real-life environment (for example placing posters, diagrams on the notice board) leads the student into the realms of imagination as the learning process ‘. . must take place in contexts that resemble the situations in which the knowledge and skills will be used' (Johnson 1997). The computer lab should be equipped with an appropriate network facility (Gloster and Saltzberg 1996) 
lights and have a printer, scanner and/or copier machine. The arrangement of furniture is necessary to provide an opportunity for individual learning, cognitive apprenticeship and group discussions. In addition, a quiet atmosphere should be organised and a place should be provided to keep statistics, journals, documents, reference and library books, encyclopaedias and magazines.

(b) Learning support: Educational media (for example, the visual organizer on the board) help students, during discussions and brainstorming, to list ideas, plan steps for practice and list the requirements and actions necessary for each stage of the technological process (Jakovljevic 2002) are productive approach to promote ISD could be achieved by developing the following off-line material:

- a web design checklist (WDC);

- a web evaluation checklist (WEC);

- a performance indicators checklist (PIC);

- problem-solving guidelines (PSG);

- decision-making guidelines (DMG);

- creative thinking guidelines (CRG);

- critical thinking guidelines (CTG);

- collaborative group guidelines (CGG); and

- worksheets.

(c) Graphical techniques: In facilitating the understanding of key business processes and requirements it is necessary to introduce different graphical techniques: synthesisers, advanced organisers, historic and emerging organisers and the columnar data flow diagram (CDFD). For example, the purpose of the CDFD is to visually depict procedural knowledge pathways (Mende and Mohomed 2000). Boden, (1990) suggests that vision is the most powerful human sense, having 'evolved to notice spatial relations such as connectedness, juxtaposition and gaps', which can be applied in the ISD context.

(d) Hardware: The computer lab should be equipped with appropriate desktop computers. For example, Pentium 3 with 20 GB hard drive, network cards and 14 " monitor.

(e) The software tools: Many students have no experience or knowledge on how to use software tools to represent personal interpretations (Jonassen 1996). The following mind tools have been introduced to form an appropriate environment for teaching and learning ISD:

- Semantic networks are special representations of ideas and their interrelationships within the human memory structure (Jonassen, Beissner and Yacci 1993; Jonassen 1996). Von Wodtke (1993) states that semantic diagrams by means of their visual power help to articulate concepts and relationships between concepts, forming new insights into relationships between them. 
- Computer mediated communication (CMC) serves as a vehicle for delivery and sharing the product of any mind tool between students (Jonassen 1996). Using CMC makes activities independent of time and place, allowing messages to be sent, received and '. . . discussions can proceed in a more non-linear, simultaneous fashion' (McMahen and Dawson 1995).

- According to Swan and Black (1990), computer programming is a problemsolving tool if particular problem-solving strategies (for example, problem decomposition, generating hypotheses, and gathering evidence to support those hypotheses) are applied to real world-problems. Dover (1983) points out that computer programming facilitates the development of abstract thinking, problem solving and logical thinking.

- In addition, a preliminary selection of the appropriate software technology must be made in order to integrate the visual design with functionality based on the preference and the existing hardware requirements (Jakovljevic 2002):

- The development platform architecture (for example, Windows operating system, Personal Web Server (PWS), Active Server Pages (ASP), The database (MS Access), the Internet browsers (Internet Explorer/ Netscape Navigator))

- The development application architecture (for example HTML, JavaScript, Cascading Style Sheets (CSS), Java Applets)

- The production platform architecture (for example, Windows NT, IIS (Internet Information Server), Active Server Pages (ASP)) (Greenberg and Lakeland 1999)

- Time: Literature confirms the importance of time constraints in learning (Whitney 1987; Hill 1998). The idea of time constraints and time planning for each phase and deliverable of ISD (Jakovljevic 2002) are crucial elements of an appropriate environment for ISD.

In the next section, we focus on the network of human resources that relies heavily on physical resources for effective teaching and learning in an ISD context.

\section{The network of human resources}

Creating a multi-method learning environment is possible, if a network of human resources (lecturer, a senior tutor, peer-tutors, an assistant, technical assistant) is available in an ISD context:

(f) The lecturer should acquire different roles (such as: mediator of learning, interpreter and designer of learning programmes and materials, learning area/ subject/discipline/phase specialist) and competences (foundational, practical and reflective competences) (Jakovljevic 2002). 
(g) The lecturer should have essential instructional skills (for example, organizational, instructional alignment, focus, feedback, monitoring, communicational, questioning) and positive affective characteristics (for example, enthusiasm, modelling, warmth, empathy and a positive frame of mind) (Jakovljevic 2002).

(h) The lecturer should be well equipped with project management competences (business achievement competences, problem-solving competences, influence competences, people-management competences, self-management competences) (Whitten, Bentley and Dittman 2004).

(i) A teaching assistant provides individual guidance and group tutoring in a time and place convenient for students; must be familiar with practical and cognitive apprenticeship. A teaching assistant should have a proven record of knowledge and skills in system design and reinforce the social-interaction and system design skills of students. The teaching assistant allows intrinsic feedback on the description (Laurillard 1994). An assistant coordinates the actions of peer-tutors.

(j) Peer-tutors teach a topic, skill or concept to members in the group or across the different groups according to a time schedule.

(k) A technical assistant is an expert involved in providing expertise in terms of technical knowledge and skills for software and hardware.

By delegating practical responsibilities to a teaching assistant, technical assistant and peer-tutors, the lecturer is provided with more time to be involved in cognitive apprenticeship. The learning experience of ISD is enriched through social interactions as students interact with experts in the project-based classroom. Taking into consideration the above human network the success of teaching and learning in an ISD context is determined by appropriate financial management and financial and administration skills of the lecturer.

\section{Administration and financial skills of the lecturer}

Due to its complexity an ISD context demands extensive administrative involvement of the lecturer (Jakovljevic 2002). The intent of financial management is to assist the lecturer to deploy physical resources and apply her financial knowledge and skills of managing ISD. Financial funds should be available to organize and manage the computer lab, to handle students' fees and the remuneration of contract personnel, for example, an assistant and the technical assistant. The financial planning must be done in advance and financial skills in managing financial funds are essential for creating an appropriate environment of ISD.

An appropriate environment for ISD is organized in terms of the following: physical resources environment are deployed; a network of human resources is organised; financial resources are appropriately planned and managed. 
Although these resource components coexist in an ISD context, there is no literature that identifies how they are integrated into a learning programme, which could further improve the teaching and learning of ISD concepts and procedures. Therefore, this gives rise to a lack of understanding of a suitable framework for an effective ISD.

The next section will indicate how the resource components, which could enhance teaching and learning in an ISD context, were incorporated within the Instructional Web Design Programme (IWDP).

\section{Incorporating the resource components in the Instructional Web Design Programme (IWDP)}

The three pillars of the theoretical framework (mind tools, complex thinking, instructional models and strategies), serve as a basis for the derivation of criteria for the development of the Instructional Web Design Programme (IWDP) (Jakovljevic 2002 and 2004). 'Complex thinking includes goal-directed, multi-step strategic processes, such as designing, decision making and problem solving and this is an essential core of higher-order thinking' (Jonassen 1996). The term proposed for the purpose of this research is 'complex thinking' as an umbrella term under which all other sub-processes (creative thinking, critical thinking, decisionmaking, problem solving and design) and skills of higher-level thinking belong (Jakovljevic 2002).

In addition, policy related to technology education and Outcomes-Based Education in South Africa; the conceptions of the Illustrative Learning Programme (DoE 1999); the roles and competencies of the lecturer in a technology classroom serve as the further basis underlying the derivation of the IWDP (Jakovljevic 2002). Policy related to technology education and Outcomes-Based Education in South Africa highlights the necessity to meet the critical learning outcomes (DoE 1997a; South Africa 1997) and specific learning outcomes (Jakovljevic 2002) in any learning area including ISD.

The IWDP consists of the following components whose characteristics are shaped by criteria embedded in the theoretical framework on mind tools, complex thinking, instructional models and strategies (Jakovljevic 2002):

- Theme.

- Critical outcomes (CO's): Critical outcomes are generic cross-curriculum outcomes, which ensure that students acquire the skills, knowledge and values, which influence their own success and contribute to a wider community (DoE 1996).

- Specific outcomes (SO's) include technological knowledge, skills, attitudes and values that help students to understand and demonstrate achievements in technological contexts.

- Assessment criteria (AC) help to evaluate the processes (cognitive and behavioural) and indicate in broad terms the observable products of learning. 
- Range Statements (RS) indicate the scope, depth, and level of complexity of content, processes and contexts which students should engage with, as well as parameters of the achievement (DoE 1997a).

- Performance indicators (PI) assist the lecturer and students by providing details of the content and processes that a student should master.

- Case study tasks help students to connect classroom activities with reality.

- Resource tasks guide students through a variety of means (graphical techniques and mind tools) through which they acquire technological knowledge, creative, reflective and problem solving skills.

- Capability tasks spread across the stages of the technological process, which help students to apply acquired knowledge and skills.

- 'Notional time represents contact time, students' efforts and time, preparation time and other issues' (DoE 1997A).

- Learner off- and on-line activities are allocated for each task during the technological stages.

- Teacher activities (Instructional strategies) (Ankiewicz, De Swardt and Stark 2000; Jakovljevic 2002; Reddy, Ankiewicz and De Swardt 2003).

Additional components of the IWDP are the stages of the technological process (Jakovljevic 2004). The technological process (procedural knowledge) includes the following ten stages: statement of the problem; design brief; investigation; proposal; initial ideas; research; development; planning; realisation/making; testing, evaluation and improvement (Ankiewicz, De Swardt and Stark 2000). The stages of the technological process are cyclical and repetitive. 'Design, modelling, problem solving, systems approaches, project planning, quality assurance and optimisation are all candidates for technological procedural knowledge ... ( McCormick 1997; Ankiewicz 2003).

The resources, which could enhance teaching and learning in ISD could be incorporated with the components of the IWDP.

Time as a component of physical resources was allocated within the IWDP as the lecturer planned an approximate time for each stage of the technological process. No detailed time planning for the learner task and activities was performed.

Learning support was facilitated through a set of learner tasks and off-line activities. By providing structured tasks (Ankiewicz 2003) and activities, the student has an opportunity to get an overview of the system. 'Favourable conditions for learning exist when a person is faced with a task for which no known procedure is available' (Wheatley 1991). Tasks should be given according to the ability level of students as well as prior experience (Johnson 1997).

Software tools (for example mind tools) and graphical techniques were taught through the predefined set of learner tasks and on-line activities and their corresponding teacher activities (instructional strategies).

The network of human resources (lecturer, a teaching assistant, peer-tutors) was 
provided with the pre-defined set of AC, RS and PI embedded within the IWDP. A variety of pre-defined teacher activities (instructional strategies) were incorporated into the IWDP guiding the lecturer through the complexity of organising an appropriate atmosphere for creativity and problem solving in a constructivist classroom.

Learning outcomes (critical (CO's) and specific outcomes (SO's) were communicated to students before the implementation of the IWDP. Clear communication of the learning outcomes could improve students' intrinsic motivation and individual responsibilities during the ISD (Jakovljevic 2002).

A variety of learning approaches (for example, individual, collaborative, situated learning, inquiry learning, apprenticeship learning, peer learning, observational learning and experiential learning) was promoted through the provision of learner tasks (case studies, resource and capability tasks) within the IWDP (Jakovljevic 2002). Important aspects of informal learning, contextual learning, peer-based learning, activity-based and reflective practice (Johnson 1997) are incorporated in the project-based classroom, which could contribute to the effective creation of positive learning and teaching atmosphere.

The IWDP emphasized the need for the development of learners' research skills during the stages of the technological process (Jakovljevic 2005). The research framework enables learners to utilize a holistic approach towards problem solving (Roode 2005).

This research assumes that the provision of different instructional strategies and learning approaches based on constructivism and behaviourism will extend students' cognitive capabilities and ISD skills. The knowledge and tools from computer science and engineering, psychology and sociology, management and anthropology contribute in addressing problems in the IS field (Roode 2005). In addition the knowledge and tools from the instructional methodology set in the IWDP could also contribute in addressing problems in the information systems field (Jakovljevic 2002).

The IWDP was implemented in a computer lab, which served as a constructivist classroom where multiple interactions were possible reflecting individual and group dynamics and a variety of learning approaches and teaching strategies. Constructivists emphasise that students need to be actively involved, to reflect on learning and to make inferences (McCormick 1997; Winn 1990). Furthermore, behavioral principles on learning and instruction in a constructivist classroom were incorporated during ISD (Jakovljevic 2002; Johnson 1997).

The IWDP contains instructional strategies for the purpose of explicit teaching of thinking skills and their attributes. One of the possible ways was to explicitly teach thinking skills in order to make students aware of thinking processes and to develop their responsibilities to monitor and understand their thinking processes. Different thinking skills and their attributes (Beyer 1984, 1991) were emphasised, explicitly explained and modelled to students during ISD. Students dealt with the conceptual meaning and attributes of thinking skills in the ISD context. 


\section{RESEARCH DESIGN}

\section{Research approach}

This research can be described as a qualitative, single case study (Yin 1994; Merriam 1998; Creswell 1994). Action research was applied to simultaneously investigate and create changes during ISD with new instructional strategies and tools.

\section{Profile of the students, intervention and setting}

In this study two distinct mixed cultural groups of students were identified. These consisted of five second-year students ( 2 females and 3 males - average age of 20) enrolled for the Information Systems Diploma at a Technikon, 12 first-year students ( 5 females and 7 males - average age of 19) enrolled for the International Diploma in Computer Studies at a Higher Education Institution. Participants from the two groups presented a purposive convenient sample (Merriam 1998). The purpose of choosing a small non-random sample was based on the researcher's intent to understand the phenomenon in depth (Merriam 1998).

The researcher of this study organised an extra-curricular classroom in a well equipped computer centre at a university and presented the IWDP in order to teach students web design and to facilitate complex thinking (Jakovljevic 2002). The IWDP was presented once a week for 13 weeks, with duration of four hours per session. Students worked on a real-world project that consisted of a car-purchasing scheme.

\section{Data-gathering methods and analysis of data}

The lecturer conducted the classroom observations, which relate to an extensive description of the lecturer's actions, thoughts and feelings related to instructional strategies, events, words and interactions of students in the project-based classroom.

An experienced interviewer conducted the retrospective interview with the lecturer and a focus group interview with the students. Students expressed their expectations of the intervention through an essay administered at the beginning of the course. They also expressed their experience with regard to the IWDP through journals written after each session of the course. Their experience of the adaptation of instruction was recorded in another essay during the IWDP.

Data were gathered through multiple data-gathering methods which satisfy the criteria for triangulation. The constant comparative method was applied to the data within interviews and between interviews (Merriam 1998). The following measures were used for judging the validity of the research design: reliability, construct validity and internal validity (Yin 1994, Merriam 1998, Creswell 1994). 


\section{RESULTS}

The scope of this article will only present and discuss findings relevant to resources that could enhance teaching and learning processes in an ISD context. The following table presents categories derived from the lecturer's and students' experience of the IWDP:

Table 1: Categories relevant to teaching and learning in the ISD context

\begin{tabular}{|l|l|}
\hline Teaching in the ISD context & $\begin{array}{l}\text { (a) Available physical resource components set a basis for the } \\
\text { efficient teaching of concepts and procedures related to ISD } \\
\text { (b) The network of human resources assisted the lecturer with } \\
\text { monitoring, teaching and administration tasks, enhancing } \\
\text { teaching and learning of ISD } \\
\text { (c) Planning and managing of financial resources by the lecturer } \\
\text { are essential for enhancing teaching and learning in ISD } \\
\text { context } \\
\text { (d) A pre defined set of AC, RS, PI, learner tasks and activities } \\
\text { and a variety of the teacher's activities set a basis for efficient } \\
\text { teaching of ISD } \\
\text { Students' understanding of } \\
\text { ISD procedures }\end{array}$ \\
(e) The physical resources provided the opportunity for the \\
students to acquire understanding of concepts and techniques \\
related to ISD \\
(f) The network of human resources helped students to extend \\
their knowledge and understanding of ISD procedures
\end{tabular}

\section{Findings regarding teaching in the ISD context}

Emerging from the interview and classroom observations relating to the lecturer's experience of the IWDP, the following findings were made:

- Available physical resource components set a basis for the efficient teaching of concepts and procedures related to ISD

The lecturer wrote that the allocated computer lab with its equipment (a printer, arrangement of furniture, light fitment, hardware and software tools) provided a quiet and stimulated atmosphere for teaching ISD. Computers were placed in rows with flexible arrangements of chairs and a technical assistant desk was placed in the corner. Students were seen moving around and freely arranging their space and learning groups.

The lecturer observed that: ' $\ldots$. there was hardly any problem with software or hardware, as two assistants ... . [a teaching assistant and a technical assistant] were present all the time'.

During classroom observations the lecturer noted that the careful planning of learning support (for example, visual aid on the board, worksheets, checklists, guidelines) and graphical techniques (for example, CDFD) contributed to the 
students' imagination, full concentration, and reflection. This was evident through careful gathering and filing of the off-line material in their project files. It was also evident through their complete engagement during the ISD and their loud thinking and reflection during group discussions.

The lecturer, however, reported that there was insufficient time allocated for some of the technological stages: 'They were coming once a week ... Students need more time for design . . . there was no time for modelling . . . More time should be allocated for the teaching of thinking skills and their attributes'.

- The network of human resources assisted the lecturer with monitoring, teaching and administration tasks, enhancing teaching and learning of ISD

The lecturer, commented in the observation protocol: ' $\ldots$. while I helped to form collaborative groups and to perform cognitive apprenticeship an assistant was involved with monitoring of team-building activities providing an explanation and demonstration of ISD concepts and techniques ...'

Observation notes revealed that the lecturer helped a teaching assistant in discussions with students. Topics covered were: how to set ground rules, model discussions, and how to master questioning techniques using questions such as (what is, how does, how should, why is, where is). The lecturer presented, demonstrated and discussed thinking skills and their attributes with students.

The lecturer noted: ' . . . an assistant helped with on-line resource material (the Internet knowledge base) software programmes and off-line material (handouts, library books, magazines) . . . the assistant helped me to handle administration tasks . . . checking payments, making copies etcetera . . '

- Planning and managing of financial resources by the lecturer are essential for enhancing teaching and learning in ISD context

The lecturer wrote in field notes '. . . too many administration tasks, I don't have time ... I have to check payments every day . . ? Classroom observations indicate that the lecturer experienced the difficulty in handling financial matters. The time and tasks were not allocated within the IWDP, which put additional pressure on teaching ISD. The lecturer was relieved when a teaching assistant provided help with some financial tasks at the beginning of each session.

The lecturer noted during classroom observations that managing financial resources was an essential prerequisite for a successful web design course.

- A pre-defined set of AC, RS, PI, learner tasks and activities and a variety of teacher's activities set a basis for efficient teaching of ISD

The lecturer commented that: '. . . it was very important to have a structure consisting of tasks, activities, assessment criteria, performance indicators . . . as well as a variety of the teaching actions which helped me to organise the work and to lead them towards thinking ... with the structured work students had the 
feeling that they were being guided and had more time for research and solving the problem ...?

The lecturer observed that, it was difficult to interrupt students, as they were completely occupied in dialogues, and discussions. Students' engagement with dialogues and discussions were attributed to a variety of pre-defined learner activities and a variety of lecturer's instructional strategies. Students were actively involved in the research activities guided by the set of pre-defined tasks using available physical resources and a variety of off-line and on-line tools.

\section{Findings regarding students' understanding of concepts and techniques in the ISD context}

Emerging from the interview, journals and classroom observations relating to students' experience of the IWDP, the following findings were made:

- The physical resources provided the opportunity for the students to acquire understanding of concepts and techniques related to ISD

Students commented in the focus group interview: 'when you're designing a web page, there is a lot of tools that you can use to design it, we experienced a lot of things, we had to interview managers ... we found material on the Internet, there are different applications that you can use'.

The lecturer noted in the observation protocol: 'Students tried to use standard data flow diagrams but they were complaining, destructing other students, frustrated, turning pages and telling that they see only fragments ... I felt that the columnar data flow diagram also raised their self-confidence in system design and helped them to visualize the intended system'.

The lecturer observed that students were not easily distracted in the computer lab. Available physical resources supported students during the implementation of the IWDP. They were moving around the groups in the need for explanations and demonstrations of ISD techniques. They were also sitting in pairs, talking loudly while drawing the sketches, exchanging magazines, documents, books and other learning support material.

Students, however, commented in the focus group interview regarding the allocated time: 'We need more formal time ... we spend a lot of time on first two stages ... we had time to think about the problem and investigate ...? Students commented in their journals: 'There is little time left for us to complete work . . ?

- The network of human resources helped students to extend their knowledge and understanding of ISD procedures

Students noted in the focus group interview that: 'only in class there was somebody, right Maria was there, but when we met up on our own ... we need more guidance ...? 
Students further commented, ‘. . . after having done ... your research . . . then your decision-making session will be based on this which option do I use ... on the results of reflective thinking ... you do the research and then you do the decision-making. You decide on what you going to do, speak to the members of your group and you come up with something'.

Notes written in journals revealed that other students helped each other with ISD tasks and activities: 'George helped me . . . we helped each other . . '

Observation notes revealed: ' . . . they often called an assistant [a teaching and/or technical assistant] to explain a procedure . . . or when they experienced a problem (for example with mind tools, Windows, an application) . . ?

\section{DISCUSSION}

From the results, and as an answer to research question 1, the resource components that could enhance teaching and learning in ISD are allocated within physical, human and financial resources.

Physical resource components with appropriate interaction between human resources should be planned and managed within an appropriate time unit to avoid students' comments such as 'you see we were under pressure with time, we didn't have time to do much, we only had one class a week ...?

Interaction between a network of human resources (lecturer, assistants and peer-tutors) is crucial not only for knowledge sharing but for the promotion of critical and specific outcomes (DoE 1996; South Africa 1997). In the complex learning environment such as ISD; exchange of roles, close monitoring and assessment are expected tasks of human resources.

In considering IS applications the focus is on 'the individual's task productivity while underestimating the importance of the social context' which leads to 'inappropriate application designs . . ? (Lyytinen and Ngwenyama 1992; cited by Roode 2005). The results reveal that the information systems design is a collaborative activity, which requires an organized social context in which communications with human resources play the major role. When attempting to find a solution to the real-world problem in the information systems field learners used questioning techniques (what is, how does, how should, why is) which is supported in the literature (Roode 2005; Jakovljevic 2005).

The help provided by a teaching assistant with regard to administration and some financial tasks relieved the organisational burden from the lecturer, which lead greater focus on the facilitation of technological problem solving.

The findings indicate that to cater for the resource components of an ISD environment students were guided through AC, RS, PI and a set of pre-defined learner tasks and activities and teacher activities embedded within the IWDP (as an 
answer to research question 2). Perhaps the resource components that could enhance teaching and learning in an ISD context were only effective through their sensitive integration within the IWDP.

Providing multiple resources (physical, human and financial) and simulating the students' real environment through a variety of learning approaches (for example, individual, collaborative, situated learning, inquiry learning, apprenticeship learning, peer learning, observational learning and experiential learning) and a variety of teacher activities to choose from (for example, explanation, demonstration, modelling, questioning, discussions, dialogues, inquiry/investigation, lecture, whole class instruction) was possible through the pre-defined coherent structure of the IWDP. The findings reveal that the social context was intense with interactions, communications and questioning. The lecturer emphasized the importance of the enhancement of research skills in the information systems field. This influenced the understanding of concepts and technique relevant to information systems and the student's self-motivation (as an answer to research question 3).

During the implementation of the IWDP, multiple learning approaches and teaching activities improved the students' understanding of ISD design procedures (Jonassen 1996).

The integration of the resource components that could enhance teaching and learning with the components of the IWDP further enriches the value of the learning programme, which in turn could create an atmosphere for reflective learning (Lohman 2000). Students analyzed the problem from different perspectives helped by a network of human resources in an organized physical environment. In this way they could extract a rich body of information and experience multi-method learning in the IS design context (Roode 2005).

In addition to the relevance of necessary resources in the IS design context learners should 'utilize the different paradigms (for example, the interpretive paradigm, the radial humanist paradigm) to view the problem at hand deliberately from different perspectives. Only in this way can the uniqueness of each problem situation be appreciated holistically to arrive at appropriate "solutions"' (Roode 2005).

\section{IMPLICATIONS FOR TEACHING AND LEARNING IN ISD CONTEXT}

Some specific implications were derived in the attempt to create an appropriate environment for ISD:

- Physical resources: Organizing an appropriate venue, learning support (educational media, graphical techniques, off-line material), hardware and software (mind tools and application software) within an appropriate time frame is an essential basis for an effective learning and teaching ISD context.

- Mind tools (for example, semantic networks, CMC, programming) and 
graphical techniques (for example, advanced organisers, historic and emerging organizers, CDFD) help students to understand ISD concepts and techniques.

- The network of human resources provides an interactive learning and teaching environment through sharing of roles and responsibilities. Teaching and administration tasks should be divided between the lecturer, peer-tutors and a teaching assistant. A wider human network should be created in an ISD context including peer-tutors, a senior tutor and a technical assistant.

- The lecturer should have instructional and project management skills encouraging interactions between human resources. In addition, the lecturer should possess positive affective characteristics, multiple roles and competences in an ISD context.

- Financial resources: Several financial resources exist within an ISD context. Only through the accommodation of the teacher's activities (which deal with financial matters) within the IWDP and the sharing of responsibilities between assistants could help lecturer to concentrate on individual and cognitive instruction.

- Pre-defined set of instructional strategies, $A C, R S$ and PI: A range of predefined teacher activities based on both behavioural and constructivist learning as well as instructional principles empower the lecturer to create an appropriate climate for teaching ISD.

- A pre-defined set of learner tasks and activities becomes a prerequisite for creativity, promoting active learning and students-centred learning.

- Multi-method learning experience: The nature of an appropriate environment for ISD which reflects a variety of learning approaches (for example, situated and experiential learning) as students extend their knowledge and skills through the exposure to real life situations beyond the actual project-based classroom.

In this article we present empirical evidence that specific physical, human and financial resource components are required to enhance teaching and learning processes for understanding information system design. The instructional programme may serve as orientation for students and the lecturer in the ISD context.

Although this work is presented in the context of an undergraduate web design course, we note that the effort also can be used to enhance understanding of information system design in a corporate environment.

\section{REFERENCES}

Ankiewicz, P. J. 2003. Technology education at school: illusion or reality? Inaugural address by Prof. P. J. Ankiewicz, Johannesburg. Rand Afrikaans University. 15 October 2003.

Ankiewicz, P. J., A. E. de Swardt and R. Stark. 2000. Technology education: principles, methods and techniques of technology education I. Johannesburg: RAU College for Education and Health. 
Beyer, B. K. 1984. Improving thinking skills practical approaches. Phi Delta Kappan 65 (8): 556560.

. 1991. Teaching thinking skills: A handbookfor secondary school teachers. Boston: Allyn and Bacon.

Boden, M. 1990. The creative mind. London: Weidenfeld and Nicolson.

Creswell, J. W. 1994. Research design: Qualitative and quantitative approaches. Thousand Oaks, California: Sage publications.

Department of Education. 1996. Curriculum framework for general education and training. Pretoria: Gauteng Department of Education.

. 1997a. Outcomes based education in South Africa. Pretoria: Gauteng Department of Education.

. 1997b. Draft Policy. Senior phase. Policy Document. Pretoria: Gauteng Department of Education.

. 1999. National curriculum 2005. Illustrative learning programmes grade 7. Pretoria: Gauteng Department of Education.

Dover, A. 1983. Computers and the gifted: Past, present and future. Gifted Child Quarterly 27 (2): 71 .

Gloster, A. S. and S. Saltzberg. 1996. Multimedia and asynchronous learning: Changing the support model for information technology services. Cause/Effect 19 (4): 2729.

Greenberg, J. and J. R. Lakeland. 1999. Building professional web sites with the right tools. Upper Saddle River: NJ: Prentice Hall PTR.

Hill, A. M. 1998. Problem solving in real life contexts: An alternative for design in technology education. International Journal of Technology and Design Education 8:203 220.

Jakovljevic, M. 2002. An instructional model for teaching complex thinking through web page design. D.Ed. thesis, Rand Afrikaans University, Johannesburg.

. 2004. Synergy between the technological process and a methodology for web design: Implications for technological problem solving and design. International Journal of Technology and Design Education 14:261 290.

Johnson, S. D. 1997. Learning technological concepts and developing intellectual skills. International Journal of Technology and Design Education 7:161 180.

Jonassen, D. H. 1996. Computers in the classroom: Mind tools for critical thinking. New Jersey: Prentice Hall.

Jonassen, D. H., K. Beissner and M. A. Yacci. 1993. Structural knowledge: Techniques for assessing, conveying and acquiring structural knowledge. Hillsdale, NJ: Lawrence Erlbaum Associates.

Kommers, P., D. H. Jonassen and T. Mayes. 1992. Cognitive tools for learning. Heidelberg, Germany: Springer Verlag.

Kozma, R. B. 1987. The implications of cognitive psychology for computer based learning. Educational Technology 24 (11): 2025.

Laurillard, D. 1994. Rethinking university teaching: a framework for the effective use of educational technology. London: Routledge.

Lohman, M. C. Environmental inhibitors to informal learning in the workplace: A case study of public school teachers. Adult Education Quarterly 50 (2): 83101.

Lyytinen, K. L. and O. K. Ngwenyama. 1992. What does computer support for cooperative work mean? A structural analysis of computer supported cooperative work. Accounting Management and Information Technology 2 (1): 1937.

McCormick, R. 1997. Conceptual and procedural knowledge. International Journal of Technology and Design Education 7:141 159. 
McMahen, C. and A. J. Dawson. 1995. The design and implementation of environmental computer mediated communication (CMC) projects. Journal on Research on Computing in Education 27 (3): 318335.

Mende, J. and F. Mohomed. 2000. Data flow diagrams with functional columns. Information Systems Department. Available at: http://www.isys.wits.ac.za/mende/ISD DFD.htm. Ac cessed in 2000 .

Merriam, S. B. 1998. Qualitative research and case study applications in education. San Francisco: Jossey Bass.

Reddy, K., P. J. Ankiewicz and A. E. de Swardt. 2003. The essential features of technology education: a conceptual framework for the development of OBE (outcomes based education) related programmes in technology education. International Journal of Technology and Design Education 13:27 45.

Roode, J. D. 2005. Implications for teaching of a process based research framework for Information Systems. Available at: http://hagar.up.ac.za/catts/mit/research/research.html). Accessed in 2005.

Shelly, G. B., T. J. Cashman and H. J. Rosenblatt. 2001. Systems analysis and design. 4th edition. Boston: Course Technology, Thomson learning.

Government Gazette. 1997. No 6. Pretoria: Gauteng Department of Education.

Swan, K. and J. Black. 1990. Logo programming, problem solving, and knowledge based instruction. Paper presented at the annual meeting of the American Educational Research Association, Boston, MA. ERIC document Reproduction Service No. 349968.

Von Wodtke, M. 1993. Mind over media: creative thinking skills for electronic media. New York: McGraw Hill.

Wheatley, G. H. 1991. Constructivist perspectives on science and mathematics learning. Science Education 75 (1): 921.

Whitney, P. 1987. On practice and research: confession of an educational researcher. Lifelong Learning 10 (8): 1215.

Whitten, J. L., L. D. Bentley and K. C. Dittman. 2004. System analysis design methods. New York: McGraw Hill/Irwin.

Winn, W. 1990. Some implications of cognitive theory for instructional design. Instructional Science 19:53 69.

Yin, R. K. 1994. Case study research: design and methods. Thousand Oaks, California: Sage Publications. 